\title{
Variable-interval and fixed-interval schedule preferences in pigeons as a function of signaled reinforcement and schedule length
}

\author{
SANDRA M. SCHRADER and HOWARD RACHLIN \\ State University of New York, Stony Brook, New York 11794
}

\begin{abstract}
Pigeons were reinforced for pecking on two concurrent chain schedules. The terminal links consisted of a variable-interval or an arithmetically equivalent fixed-interval schedule. For half the subjects a brief response-independent change in key color signaled reinforcement. This procedure eliminated the differences in predictability of reinforcement between the two terminal link schedules. Tested over several variable-interval and fixed-interval schedule values, the pigeons' preference for the variable-interval link varied directly with the absolute value of the arithmetic mean but independently of the signal presentation.
\end{abstract}

Herrnstein (1964a) presented pigeons with two independent, concurrent variable-interval (VI) schedules, each correlated with a different response key. He found that the relative rates of pecking on the two keys matched the relative rates of reinforcement available on the two keys. However, when one VI schedule was replaced by a fixed-interval (FI) schedule of equivalent overall rate of reinforcement, the relative response rates did not match the relative rates of reinforcement. The preference for the VI over the FI schedule was stronger than that predicted by either arithmetically or geometrically averaging the VI schedule interreinforcement intervals (Herrnstein, 1964b).

In order to measure response rates unconfounded by the different rates and patterns of responding generated by different reinforcement schedules (Ferster \& Skinner, 1957), Herrnstein's procedures used two concurrent chain schedules of two links each. During identical concurrently available initial links, the pigeon chose between the different terminal-link schedules. The relative rates of pecking du:ing the initial links measured the preference for one terminallink schedule over the other.

Killeen (1968) used concurrent chain schedules with VI and FI terminal links and found that the relative response rates matched the relative rates of reinforcement when the harmonic mean of the VI interreinforcement intervals equaled the FI interreinforcement interval. Davison (1969, 1972) compared FI and modified VI terminals links and found matching when the VI interreinforcement intervals were averaged harmonically after a transformation of the reciprocals to either the second (Davison, 1972) or third (Davison, 1969) powers. MacEwan (1972) interchanged VI and FI

This work was supported by a National Science Foundation research grant to Howard Rachlin. Reprints may be obtained from Howard Rachlin, Department of Psychology, State University of New York, Stony Brook, New York 11794. terminal-link schedules of equal harmonic means and observed only slight fluctuations in preference. However, through a series of FI-FI and VI-VI schedule comparisons, he found that preference for the smaller harmonic mean increased as a function of the absolute size of the schedules.

More recent investigations have examined the role of the predictability of the reinforcer. Frankel and vom Saal (1976) selected an FI and a twointerreinforcement-interval VI terminal link that were equally preferred by pigeons. They observed that when the VI terminal-link interreinforcement intervals were differentiated by red and green key lights, pigeons demonstrated a slight, transient preference for that schedule. Badia, Harsh, and Coker (1975) presented response-independent shocks to rats on either a fixedtime (FT) or variable-time (VT) schedule. When shocks during both schedules were either unsignaled or signaled by a 5 -sec tone, rats chose to remain in the FT schedule or to change from the VT to the FT schedule. However, when only shocks on the VT schedule were signaled, rats chose that schedule over the FT.

The Badia et al. (1975) study suggests that, under conditions of unavoidable shock, the predictability of the stimulus determines preference. Predictability in their study could be attributed both to the discrete periods of tone and to the less discrete temporal cues from the periodicity of the FT schedule. Singly, the tone was preferred to the temporal cues, but a combination of both tone and temporal cues was chosen over the tone alone.

Using procedures similar to those of Badia et al. (1975) and MacEwan (1972), the present study examines the role of the predictability of responsedependent food presentations and the effects of absolute schedule size. During the initial links of two concurrent chain schedules, pigeons chose between arithmetically equivalent VI and FI terminal links when reinforcers 
during both were either unsignaled or signaled by a brief change in key color.

\section{METHOD}

\section{Subjects}

Four adult male White Carneaux pigeons were maintained at approximately $80 \%$ of their free-feeding body weights. Subjects 27 and 28 were experimentally naive, and Subjects 18 and 19 had brief experimental histories.

\section{Apparatus}

A standard operant conditioning chamber contained two response keys which could be illuminated by $6-\mathrm{W}$ lamps and activated by a minimum pressure of approximately $12 \mathrm{~g}$. A food hopper, illuminated by $7-\mathrm{W}$ bulbs during the reinforcement periods, was located between and below the response keys. Reinforcement consisted of access to mixed grain. Two 6-W houselights illuminated the experimental chamber except during periods of reinforcement. The chamber was housed in an insulated box equipped with an exhaust fan which attenuated the sound of external events. Standard electromechanical relay equipment in an adjacent room controlled the experiment and recorded the data.

\section{Procedure}

After the naive pigeons were trained to keypeck, all birds were presented with two white keys corresponding to two independent, concurrent VI 1-min schedules. Pecks on the lighted keys produced feedback clicks. Daily sessions were terminated after the delivery of 40 4-sec reinforcements. Relative response rates on the two keys provided a baseline measure of key position biases.

During all subsequent conditions, the two response keys were correlated with concurrent chain schedules. The initial links of both chain schedules consisted of the VI 1-min baseline schedules and were signaled by a white lighted key. The terminal link of the chain schedule correlated with the left key was always a VI schedule signaled by a green key light. The terminal link of the other chain was always an FI schedule with interreinforcement intervals equivalent to the arithmetic mean of the VI schedule interreinforcement intervals. The FI schedule was signaled by a red light on the right key.

At the beginning of each session, both key lights were white. Following a completed interval of the left VI 1-min initial-link schedule, the first peck on the left key terminated the initial links. The key color changed from white to green, and the right key went dark. Pecks on a darkened key were ineffective and produced no feedback clicks. The left key remained green throughout the terminal-link component. The completion of the terminal link was followed by a 3-sec access to food. Both key lights then turned white, and the VI 1-min schedules became effective.
Following a completed interval of the right VI 1-min initiallink schedule, the first peck on the right key terminated the initial links. The key color changed from white to red, and the left key went dark. The right key color remained red throughout the terminal link. The completion of the FI schedule was followed by a $3-\mathrm{sec}$ access to food. Both key lights then turned white, and the VI 1-min schedules became effective.

Six experimental conditions were run in the same sequence for each subject. A listing of the terminal-link schedules is presented in Table 1.

In Condition 1 both terminal-link components ended after one reinforcement. In Conditions 2-6 the VI terminal link lasted a fixed duration equivalent to the FI terminal link, and the number of reinforcements during the VI terminal link varied randomly from zero to two.

Under each condition reinforcements were unsignaled for half the subjects and signaled for the other half. The signal was a response-independent key color change from either green or red to yellow immediately preceding reinforcement. The duration of the signal for each condition is listed in Table 1.

Subjects were run 7 days a week. Daily sessions terminated after 60 reinforcements. Subjects were given supplementary feedings of mixed grain in the home cage after each session as required to maintain their $80 \%$ body weights. All training and experimental conditions were terminated when a visual inspection of the graphed data indicated a stable level of performance.

\section{RESULTS}

The mean relative rates of responding over the last 7 baseline days showed a maximal deviation of .05 from indifference (.50). Preference for either terminal link was determined by the relative rate of responding during the initial links. The number of initial-link responses on one key was divided by the total number of initiallink responses on both keys.

Figure 1 shows the relative response rates during the initial link on the VI key averaged over the last 5 days of each condition for each bird. Values above .50 indicate preference for the VI terminal link. A comparison of the data from Conditions 1 and 2 indicates no systematic changes in preference following the altered VI terminal-link procedure.

Results also varied following the signal reversals between Conditions 2 and 3. Subjects 18 and 27 were changed to the signaled group, and their VI schedule preferences increased and decreased, respectively. Subjects 19 and 28 were changed to the unsignaled

Table 1

Sequence of Experimental Conditions, Length of VI Terminal Links, Duration of Signal, and Group Assignment of Subjects

\begin{tabular}{|c|c|c|c|c|c|c|}
\hline \multirow[b]{3}{*}{ Condition } & \multirow{2}{*}{\multicolumn{2}{|c|}{ Terminal Link }} & \multirow{3}{*}{$\begin{array}{c}\text { VI Terminal Link } \\
\text { Ended After }\end{array}$} & \multirow{3}{*}{$\begin{array}{l}\text { Duration } \\
\text { of Signal } \\
\text { (Seconds) }\end{array}$} & \multicolumn{2}{|c|}{ Subjects in } \\
\hline & & & & & \multirow{2}{*}{$\begin{array}{c}\text { Signaled } \\
\text { Group }\end{array}$} & \multirow{2}{*}{$\begin{array}{c}\text { Unsignalec } \\
\text { Group }\end{array}$} \\
\hline & Left Key & Right Key & & & & \\
\hline 1 & VI $30 \mathrm{sec}$ & FI $30 \mathrm{sec}$ & $1^{*}$ & 3 & 19,28 & 18,27 \\
\hline 2 & VI $30 \mathrm{sec}$ & FI $30 \mathrm{sec}$ & $30 \mathrm{sec}$ & 3 & 19,28 & 18,27 \\
\hline 3 & VI $30 \mathrm{sec}$ & FI $30 \mathrm{sec}$ & $30 \mathrm{sec}$ & 3 & 18,27 & 19,28 \\
\hline 4 & VI $15 \mathrm{sec}$ & FI $15 \mathrm{sec}$ & $15 \mathrm{sec}$ & 1.5 & 18,27 & 19,28 \\
\hline 5 & VI $6 \mathrm{sec}$ & FI $6 \mathrm{sec}$ & $6 \mathrm{sec}$ & .6 & 18,27 & 19,28 \\
\hline 6 & VI $2.5 \mathrm{~min}$ & FI $2.5 \mathrm{~min}$ & $2.5 \mathrm{~min}$ & 15 & 18,27 & 19,28 \\
\hline
\end{tabular}




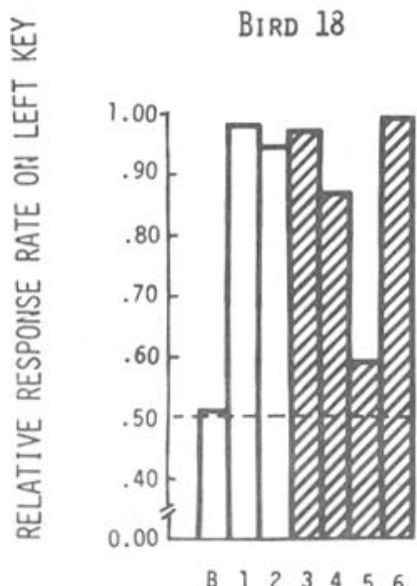

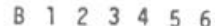

BIRD 27

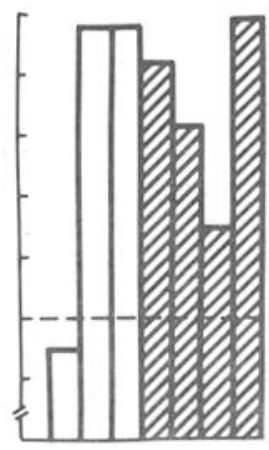

B 12234456
BIRD 19

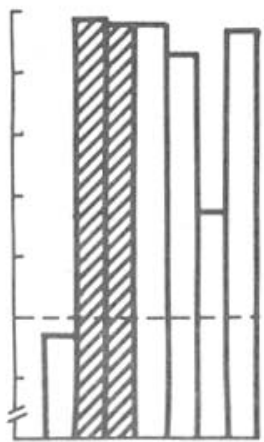

B $122345 \quad 56$
BIRD 28

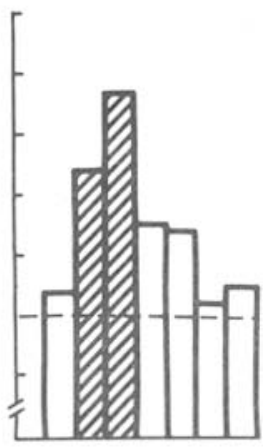

B 1223456

\section{CONDITIONS}

Figure 1. Mean relative rates of responding on the left key. Condition B (baseline): data averaged over the last 7 days of concurrent VI schedules. Conditions 1-6: initial-link data averaged over the last 5 days of concurrent chain schedules.

group, and their preferences remained unchanged and decreased, respectively.

As terminal-link schedule values decreased from $30 \mathrm{sec}$ to $6 \mathrm{sec}$ over Conditions 3, 4, and 5, consistent decreases in preference for the VI key were observed. When the schedules were increased to $2 \frac{1}{2}$ min during Condition 6, preferences for the VI key increased. Except for Subject 28, pigeons responded similarly under both signaled and unsignaled conditions. During Conditions 5 and 6 the relative response rate of Subject 28 stabilized at its approximate baseline level.

Table 2 presents the mean absolute response rates for each subject during the terminal links. Rates were averaged over the last 7 days of each condition. Response rates during the signal and in the absence of the signal are shown separately. When reinforcement was not signaled, analogous periods were used for calculation. Rates during the signal were markedly higher than rates before the signal. In the unsignaled conditions, response rates generally increased slightly during the time corresponding to the signal. Except for Subject 28, these increases were greater during the FI than during the VI schedules. Subject 28 maintained a steady response rate during the last three conditions.

\section{DISCUSSION}

The effectiveness of the signal in differentiating periods of reinforcement was evident from the differentiated response rates in the signaled group. The introduction of the signal was invariably followed by an increased response rate. ${ }^{1}$

The small increases in response rate which occurred in the unsignaled group during the periods corresponding to the signal were expected during the FI component due to the scalloped patterns of responding typically generated by such a schedule (Ferster \& Skinner, 1957).

The rate increases shown by the unsignaled group during
Table 2

Mean Absolute Response Rates (Responses/Minute) During Terminal Links

\begin{tabular}{lcccccc}
\hline & \multicolumn{2}{c}{ VI Link } & & \multicolumn{2}{c}{ FI Link } \\
\cline { 2 - 3 } \cline { 5 - 6 } Subject & Pre- & During & & $\begin{array}{c}\text { Pre- } \\
\text { signal }\end{array}$ & $\begin{array}{c}\text { During } \\
\text { signal }\end{array}$ \\
\hline
\end{tabular}

\begin{tabular}{rrrrrr}
19 & 1 & 4 & 117 & 5 & 183 \\
28 & 2 & 1 & 123 & 2 & 192 \\
& 1 & 21 & 248 & 30 & 301 \\
& 2 & 43 & 257 & 16 & 317 \\
18 & 3 & 48 & 145 & 11 & 218 \\
& 4 & 48 & 104 & 10 & 149 \\
& 5 & 43 & 85 & 14 & 94 \\
& 6 & 6 & 60 & 4 & 62 \\
27 & 3 & 4 & 282 & 1 & 298 \\
& 4 & 4 & 230 & 3 & 182 \\
& 5 & 6 & 172 & 20 & 202 \\
& 6 & 2 & 103 & 2 & 121 \\
18 & & Unsignaled Conditions & & \\
& 1 & 139 & 155 & 79 & 140 \\
27 & 2 & 156 & 171 & 88 & 140 \\
& 1 & 64 & 49 & 48 & 80 \\
& 2 & 80 & 88 & 36 & 80 \\
19 & 3 & 111 & 132 & 57 & 118 \\
& 4 & 159 & 167 & 81 & 154 \\
& 5 & 165 & 191 & 150 & 243 \\
& 6 & 62 & 67 & 36 & 72 \\
& 3 & 89 & 102 & 80 & 116 \\
& 3 & 133 & 146 & 221 & 223 \\
& 5 & 182 & 221 & 260 & 279 \\
& 6 & 84 & 88 & 44 & 58 \\
\hline
\end{tabular}

Note-Data are averaged over the last 7 days of each condition. "During signal" in the unsignaled conditions refers to the periods when a signal would have occurred under the signaled conditions. 
the VI-schedule "signal" periods can be explained in terms of the probability of reinforcement. For example, if a reinforcement was programmed at the beginning of a VI terminal link, the signaled group would receive the yellow key-light signal followed by reinforcement immediately upon entering the link. During the comparable link for the unsignaled group, subjects would receive a green light followed by reinforcement. Consequently, the probability of reinforcement was always zero immediately upon entering the VI terminal link and remained zero for the signal duration. Under unsignaled conditions, Staddon and Simmelhag (1971) found that pigeons do respond according to the probability of reinforcement. Assuming a relatively constant rate of responding from the unsignaled group, a decreased response rate immediately upon entry into the terminal link (usually a "presignal" period) would produce a slightly lowered response rate during the total "presignal" periods. ${ }^{2}$

Compared to the other subjects, Subject 28 showed little or no scalloping effect during the FI link under the last three conditions. His atypical initial link performance, especially under the last two conditions, may have been due to a failure in discriminating the periodic FI reinforcement pattern.

Reinforcement was delivered to the signaled group contingent upon a response at the completion of the signal period during both the VI and FI terminal links. As such, the responseindependent presentation of the yellow key both signaled the immediacy of reinforcement and eliminated the necessity of responding at other points during the terminal link. Because the signal was ineffective in altering the pigeons' preference for the VI schedule at any value of the schedule tested, it appears that neither the predictability of the reinforcer nor a reduced terminal-link response requirement, nor an interaction of these factors with the schedule length, contributed significantly to the VI schedule preference.

In the Badia et al. (1975) study, rats chose an FT schedule of shock when both the FT and VT schedules were either unsignaled or signaled. Based on evidence cited by the authors that choice is determined by the predictability of shock over other parameters, such as the rate of shock, one explanation of the data posits that the temporal cues of the FT schedule limited the occurrènce of shock (or the occurrence of signal and shock) to only a discriminable portion of the intershock interval. The occurrence of shock (or the occurrence of signal and shock) was equally likely throughout the VT intershock interval. The rats may have chosen the schedule with the shorter period of possible shock.

As Badia et al. (1975) note, if aversive and appetitive situations produce similar but opposite effects, the subjects under appetitive conditions should prefer a VI to an FI schedule of reinforcement. The unsignaled conditions in this study replicate the findings of Herrnstein (1964b) that pigeons do prefer the VI schedule. According to the argument above, the temporal cues of the FI schedule limit the occurrence of reinforcement (or the occurrence of signal and reinforcement) to only a discriminable portion of the interreinforcement interval. The occurrence of reinforcement (or the occurrence of signal and reinforcement) is equally likely throughout the VI interreinforcement interval. Relative to these absolute interreinforcement values, the pigeon may be avoiding the schedule with the greater period of no possible reinforcement.

\section{REFERENCES}

Badia, P., Harsh, J., \& Coker, D. C. Choosing between fixed time and variable time shock. Learning and Motivation, 1975, 6, 264-278.

Davison, M. C. Preference for mixed-interval versus fixedinterval schedules. Journal of the Experimental Analysis of Behavior, 1969, 12, 247-252.

Davison, M. C. Preference for mixed-interval versus fixedinterval schedules: Number of component intervals. Journal of the Experimental Analysis of Behavior, 1972, 17, 169-176.

Frankel, P. W., \& vom SaAl, W. Preference between fixedinterval and variable-interval schedules of reinforcement: Separate roles of temporal scaling and predictability. Animal Learning \& Behavior, 1976, 4, 71-76.

Ferster, C. B., \& Skinner, B. F. Schedules of reinforcement. New York: Appleton-Century-Crofts, 1957.

Herrnstein, R. J. Secondary reinforcement and the rate of primary reinforcement. Journal of the Experimental Analysis of Behavior, 1964, 7, 27-36. (a)

Herrnstein, R. J. Aperiodicity as a factor in choice. Journal of the Experimental Analysis of Behavior, 1964, 7, 179-182. (b)

KilleEN, P. On the measurement of reinforcement frequency in the study of preference. Journal of the Experimental Analysis of Behavior, 1968, 11, 263-269.

MacEwen, D. The effects of terminal-link fixed-interval and variable-interval schedules on responding under concurrent chained schedules. Journal of the Experimental Analysis of Behavior, 1972, 18, 253-261.

Staddon, J. E. R., \& Simmelhag, V. L. The "superstition" experiment: A reexamination of its implications for the principles of adaptive behavior. Psychological Review, 1971, 78, 3-43.

\section{NOTES}

1. It might be argued that the mere presentation of the new key color and not the association of the yellow key with reinforcement produced the increased rate of responding. No random occurrence of the yellow light was programmed for the for the unsignaled group in order to control for this possibility. However, a predictive value of the signal based on its contiguity with reinforcement is suggested by both the literature on signaled reinforcement and the observed consistently higher rate of responding throughout the stimulus period.

2. The authors express their appreciation to Dr. Leonard Green for pointing out this interpretation of the unsignaled VI terminal-link data.

(Received for publication July $31,1976$. ) 